\title{
NUMERICAL ANALYSIS FOR DETERMINATION OF HYDRODYNAMIC CHARACTERISTICS OF A GIMBALED THRUST VECTORING NOZZLE
}

\author{
SAAD ISLAM AND MD. SHAFIQUL ISLAM* \\ Department of Nuclear Engineering, University of Dhaka, Dhaka-1000, Bangladesh
}

\begin{abstract}
Gimbaled thrust vectoring nozzles are employed in Solid Rocket Motors (SRM) to account for the aspects of maneuverability of the flight vehicle. The flow field of such a solid pulsed rocket motor is explored numerically (from dome-closeout onward) by solving Reynolds-averaged Navier-Stokes equations with Menter's Shear Stress Transport (SST) k - $\omega$ turbulence model using a Computational Fluid Dynamics (CFD) tool. Parametric studies are carried out to find out the thermochemical and hydrodynamic characteristics of the hot gas in the rocket motor nozzle. The performances of different supersonic and subsonic sections were studied in terms of the hydrodynamic aspects such as static pressure and Mach number distribution. It is observed that the tradeoff of implementing thrust vectoring mechanism amounts to an additional pressure loss of $10.06 \%$ in the rocket motor. Such analyses are specific to certain types of Short Range Ballistic Missiles (SRBM) having solid state propellant (primary stage) in radial boost, end burning pulsed configuration with exacting demands on maneuverability and control implied upon payload and mission criterion.
\end{abstract}

Key words: CFD tool, Gimbaled thrust vectoring nozzle, Hydrodynamic characteristics, Solid pulsed rocket motor, SRBM

\section{NOMENCLATURE}

$\begin{array}{ll}\text { A } & \text { Area }\left(\mathrm{m}^{2}\right) \\ \mathrm{c}_{\mathrm{p}}, \mathrm{c}_{\mathrm{v}} & \text { Heat capacity at constant pressure, volume }(\mathrm{J} / \mathrm{kg}-\mathrm{K}) \\ \mathrm{h} & \text { Heat transfer coefficient }\left(\mathrm{W} / \mathrm{m}^{2}-\mathrm{K}\right), \text { Specific enthalpy (energy/mass) } \\ \mathrm{I}_{\mathrm{sp}} & \text { Specific Impulse }(\mathrm{m} / \mathrm{s}) \\ \mathrm{J} & \text { Mass flux; diffusion flux }\left(\mathrm{kg} / \mathrm{m}^{2}-\mathrm{s}\right) \\ \mathrm{k} & \text { Thermal conductivity }(\mathrm{W} / \mathrm{m}-\mathrm{K}), \text { Mass transfer coefficient } \\ \mathrm{l}, \mathrm{L} & \text { Length scale }(\mathrm{m}) \\ \mathrm{m} & \text { Mass }(\mathrm{kg}) \\ \mathrm{M}_{\mathrm{w}} & \text { Molecular weight }(\mathrm{kg} / \mathrm{kmol}) \\ \mathrm{M} & \text { Mach number }\end{array}$

* Corresponding author: <msislam@du.ac.bd>. 


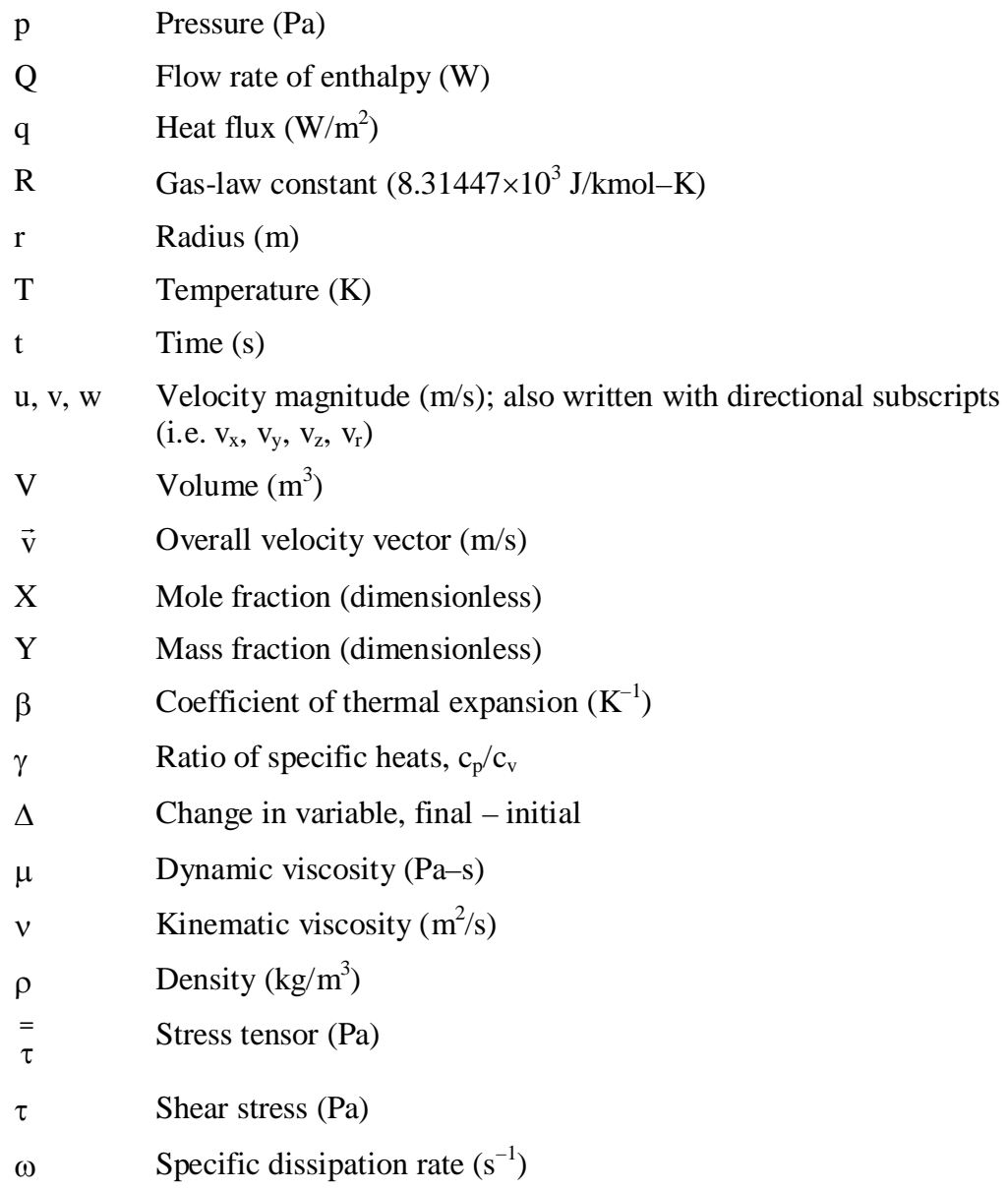

\section{INTRODUCTION}

In a Solid Rocket Motor (SRM), the combustion chamber contains solid propellant consisting of a composition that generates energy by burning the solid mass in a predictable fashion and maintain a design chamber pressure while undergoing chemical reactions. The exhaust gases are accelerated through a nozzle. The rocket nozzle is attached to the end of the motor case. It controls the flow of gases, converting the chemical energy released from combustion into kinetic energy and generates a thrust force.

The structural components include a housing which is the overall structure of the nozzle. Downstream of the motor case and upstream of the throat is a convergent dome closeout section where the flow area is reduced and the speed of the subsonic exhaust gas is increased as it is channeled to the throat. A blast tube resides downstream of the dome 
closeout, as it provides for the additional volume to flight control actuators and additional package subsystems. The nozzle throat, with the smallest internal diameter of the assembly, channels the exhaust gas to pass through a minimum flow area to reach the speed of sound. Downstream of the throat the gases expand in the exit cone to supersonic speed. Finally, the exit plane is at the end of the exit cone, where the static pressure of the gas is ideally nearly equal to the atmospheric pressure (Sutton 2001).

The present study is concerned with certain types of Short Range Ballistic Missiles (SRBM) which have SRMs employing solid state propellant in radial boost, end burning configuration in pulsed mode. The maneuverability specific to the payload and mission criteria is derived from blast tube mounted gimbaled thrust vectoring rocket nozzle. From dome-closeout onward, the flow field of the exhaust gases through the solid (pulsed) rocket motor is explored numerically by solving Reynolds-averaged Navier-Stokes equations with Menter's Shear Stress Transport (SST) k - $\omega$ turbulence model using a CFD tool like FLUENT. Parametric studies are carried out to figure out the thermochemical and hydrodynamic aspects of the hot exhaust gas in the rocket motor nozzle.

Carlson and Hoglund (1964) carried out studies on particle drag and heat transfer in flow regimes such as in solid propellant rocket exhausts. A classical work was done by Chow and Jin (1991) on flow modeling in SRM. Blast tube effects on internal ballistics were studied by Tahsini and Ebrahimi (2006) using unsteady quasi one-dimensional conservation equations. Such analyses were taken into account while designing the nozzle geometries as well as the basis for the selection of materials. Detailed flow simulation is not reported adequately in the literature. Again the thrust vectoring features on CFD analysis were not taken into account. In this study, the performance of different supersonic and subsonic sections were studied in terms of the hydrodynamic aspects such as static pressure and Mach number distribution.

\section{NOZZLE GEOMETRIES AND MESH GENERATION}

The geometry of the rocket motor from dome-closeout onward is shown in Fig. 1. Low-carbon austenitic stainless steel ASTM 316L/UNS S31603 is considered as the housing material with inside housing insulation to maintain structural integrity. Silicone elastomer is taken as the insulation insert in the dome closeout housing to withstand a high heating with high chamber pressure and long duration. The blast tube length is taken to be tentative as a necessity to account for the additional volume to package subsystem and the diameter is modulated to render the local Mach number less than 0.8. Blast tube geometry does not contribute significantly in the overall thrust and specific impulse in the 
rocket motor. The material alternatives for the blast tube are the same as those for the dome closeout. Because of the high erosion at the throat, molybdenum is used as a refractory metal insert at the throat of the high performance motor. The exit cone is contoured to provide higher specific impulse $\left(\mathrm{I}_{\mathrm{sp}}\right)$. The exit cone material alternatives are the same as those for the dome closeout. Graphite/phenolic insert may be considered instead (Fleeman 2001).

Structural geometries are provided in a dimensionless form. The subsonic and supersonic area ratios are 30.25 and 12.25, respectively. Tangential relationships are maintained between the different quadratic and linear portions of the cross-section and is differentiable everywhere except at the endpoints of the geometry.

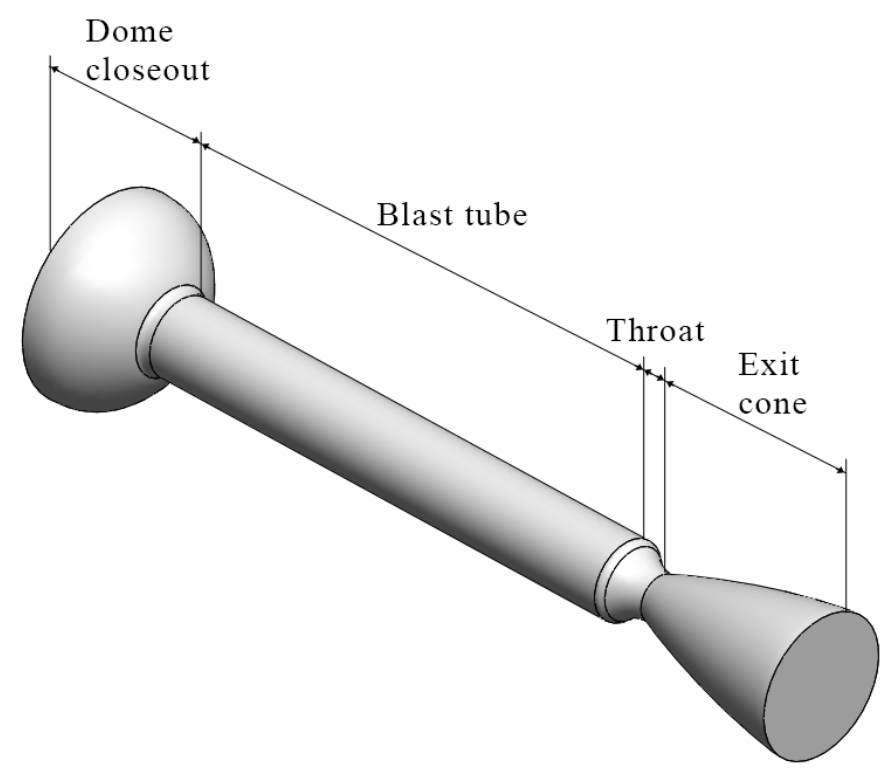

Fig. 1. Nozzle geometry.

The entire geometry is constructed in a 3D modeling software SOLIDWORKS and is imported as a CAD model for mesh generation. Unstructured grids are generated for finite element analysis and to implement corresponding algorithms. In order to capture boundary layer, the grid contains hexahedral elements near the wall. The grid distribution of the blast tube mounted nozzle is shown in Fig. 2. To avoid adverse effect on convergence and accuracy the mesh has optimized to have smooth and gradual transitions between areas of different mesh density. 


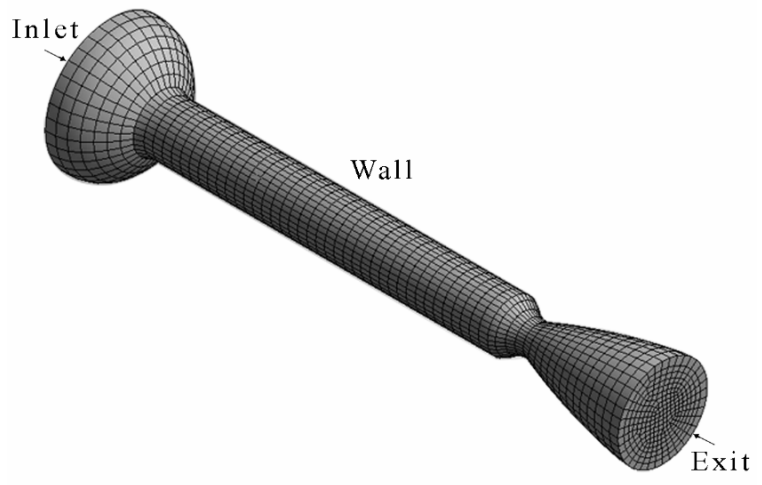

Fig. 2. Unstructured hexahedral grids after meshing.

\section{METHODOLOGY FOR COMPUTATION}

Using the CFD tool, three dimensional Reynolds Averaged Navier Stokes (3DRANS) equations are solved. Quantities at cell faces are computed using a multidimensional linear reconstruction approach employing second-order upwind scheme to discretize convective terms. In this approach, through a Taylor series expansion of the cell-centered solution about the cell centroid, a higher-order accuracy is achieved at cell faces. The details of the governing equations, thermochemical and the discretization schemes are discussed in the following subsections. Menter's SST k - $\omega$ turbulence model (Menter 1994) is used to model turbulence. The SST $\mathrm{k}-\omega$ model was developed by Menter to effectively blend the robust and accurate formulation of the $\mathrm{k}-\omega$ model in the near-wall region with the free stream independence of the $\mathrm{k}-\varepsilon$ model in the far field. To achieve this, the $\mathrm{k}-\varepsilon$ model is converted into a $\mathrm{k}-\omega$ formulation. There are several advantages in incorporating SST $\mathrm{k}-\omega$ model in the context of present study. Both the standard $\mathrm{k}-\omega$ model and the transformed $\mathrm{k}-\varepsilon$ model are multiplied by a blending function and both models are added together. The design of the blending function is such that, it is unity in the near-wall region, which activates the standard $\mathrm{k}-\omega$ model, and zero away from the surface, which activates the transformed $\mathrm{k}-\varepsilon$ model. A damped cross-diffusion derivative term in the $\omega$ equation is incorporated in the SST model. Modification is done in the definition of the turbulent viscosity to account for the transport of the turbulent shear stress. These features make the SST k - $\omega$ model more accurate and reliable for solving the problem in hand.

\section{Governing Equations}

For fluid flows, mass and momentum conservation equations are solved. An additional equation for energy conservation is solved for flows involving heat transfer or compressibility. Additional transport equations are solved too when the nature of the 
flow is turbulent. The conservation equations considered in this section is for fluid flow in inertial (non-accelerating) reference frame.

Continuity: The conservation of mass, or continuity equation can be written using Equation (1),

$$
\frac{\partial \rho}{\partial t}+\nabla \cdot(\rho \vec{v})=S_{m}
$$

Equation (1) represents the general form of the mass conservation equation which is valid for both incompressible and compressible flows. The mass added to the continuous phase from the dispersed second phase is given by the source $S_{m}$. The continuity for axisymmetric geometries is given by Equation (2),

$$
\frac{\partial \rho}{\partial t}+\frac{\partial}{\partial x}\left(\rho v_{x}\right)+\frac{\partial}{\partial r}\left(\rho v_{r}\right)+\frac{\rho v_{r}}{r}=S_{m}
$$

Momentum: In an inertial (i.e. non-accelerating) reference frame, conservation of momentum is described by Equation (3) as (Batchelor 1967),

$$
\frac{\partial \rho}{\partial \mathrm{t}}(\rho \overrightarrow{\mathrm{v}})+\nabla \cdot(\rho \overrightarrow{\mathrm{v}} \overrightarrow{\mathrm{v}})=-\nabla \mathrm{p}+\nabla \cdot(\bar{\tau})+\rho \overrightarrow{\mathrm{g}}+\overrightarrow{\mathrm{F}}
$$

where the gravitational body force and external body forces are $\rho \vec{g}$ and $\vec{F}$, respectively and $\mathrm{p}$ is static pressure given by Equation (4),

$$
\mathrm{p}=\left(\rho-\rho_{0}\right)|\overrightarrow{\mathrm{g}}|(\hat{\mathrm{g}} \cdot \overrightarrow{\mathrm{b}}-\overrightarrow{\mathrm{a}} . \hat{\mathrm{g}})
$$

where the position vectors $\vec{b}$ and $\vec{a}$ are of the face centroid and any point on the free surface, respectively. The stress tensor $\bar{\tau}$ is given by Equation (5),

$$
\bar{\tau}=\mu\left[\left(\nabla \overrightarrow{\mathrm{v}}+\nabla \overrightarrow{\mathrm{v}}^{\mathrm{T}}\right)-\frac{2}{3} \nabla \cdot \overrightarrow{\mathrm{v}} \mathrm{I}\right]
$$

where the second term on the right hand side is the effect of volume dilation, $\mu$ is the molecular viscosity, and $\mathrm{I}$ is the unit tensor. The axial and radial momentum conservation equations for axisymmetric geometries are given by Equations (6) and (7),

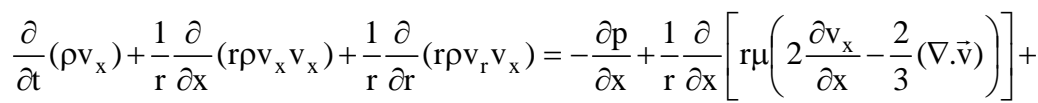

$$
\begin{aligned}
& \frac{1}{\mathrm{r}} \frac{\partial}{\partial \mathrm{r}}\left[\mathrm{r} \mu\left(\frac{\partial \mathrm{v}_{\mathrm{x}}}{\partial \mathrm{r}}+\frac{\partial \mathrm{v}_{\mathrm{r}}}{\partial \mathrm{x}}\right)\right]+\mathrm{F}_{\mathrm{x}}
\end{aligned}
$$

and

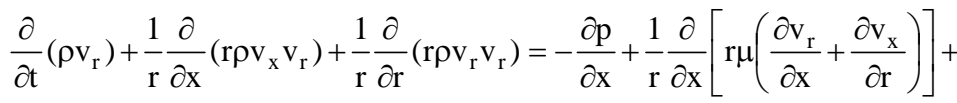

$$
\begin{aligned}
& \frac{1}{\mathrm{r}} \frac{\partial}{\partial \mathrm{r}}\left[\mathrm{r} \mu\left(2 \frac{\partial \mathrm{v}_{\mathrm{r}}}{\partial \mathrm{r}}-\frac{2}{3}(\nabla \cdot \overrightarrow{\mathrm{v}})\right)\right]-2 \mu \frac{\mathrm{v}_{\mathrm{r}}}{\mathrm{r}^{2}}+\frac{2}{3} \frac{\mu}{\mathrm{r}}(\nabla \cdot \overrightarrow{\mathrm{v}})+\rho \frac{\mathrm{v}_{\mathrm{Z}}^{2}}{\mathrm{r}}+\mathrm{F}_{\mathrm{r}}
\end{aligned}
$$


where

$$
\nabla \cdot \overrightarrow{\mathrm{v}}=\frac{\partial \mathrm{v}_{\mathrm{x}}}{\partial \mathrm{x}}+\frac{\partial \mathrm{v}_{\mathrm{r}}}{\partial \mathrm{r}}+\frac{\mathrm{v}_{\mathrm{r}}}{\mathrm{r}}
$$

And $\mathrm{v}_{\mathrm{z}}$ is swirl velocity.

Energy: Compressibility effects are generally experienced in gas flows at high velocity and/or in which there is large pressure variation. When the pressure change in the system $(\Delta \mathrm{p} / \mathrm{p})$ is large or when the flow velocity approaches or exceeds the speed of sound of the gas, the variation of the density of gas with pressure has a notable impact on the flow velocity, temperature, and pressure. Special input requirements and solution techniques must be incorporated for compressible flows as they create a unique set of flow physics.

Characterization of compressible flows can be done by the value of the Mach number given by Equation (9),

$$
\mathrm{M} \equiv \mathrm{u} / \mathrm{c}
$$

In Equation (9), the speed of sound in the gas is c which is given by Equation (10),

$$
\mathrm{c}=\sqrt{\gamma \mathrm{RT}}
$$

The flow is termed subsonic when the Mach number is less than 1.0. When the Mach number is much less than $1.0(\mathrm{M}<0.1)$, compressibility effects are negligible and in the flow modeling, the variation of the gas density with pressure can safely be ignored. As the Mach number approaches 1.0, which is referred to as the transonic flow regime, compressibility effects become significant. When the Mach number is greater than 1.0, the flow is termed supersonic, and may contain shocks and expansion fans that can impact the flow pattern significantly. Compressible flows are usually represented by the total temperature and total pressure of the flow. These quantities can be related to the temperature and pressure (static) by Equation (11),

$$
\frac{\mathrm{p}_{0}}{\mathrm{p}}=\exp \left(\frac{\int_{\mathrm{T}}^{\mathrm{T}_{0}} \frac{\mathrm{c}_{\mathrm{p}}}{\mathrm{T}} \mathrm{dT}}{\mathrm{R}}\right)
$$

For constant $c_{p}$, Equation (11) becomes,

$$
\begin{aligned}
& \frac{\mathrm{p}_{0}}{\mathrm{p}}=\left(1+\frac{\gamma-1}{2} \mathrm{M}^{2}\right)^{\gamma /(\gamma-1)} \\
& \frac{\mathrm{T}_{0}}{\mathrm{~T}}=1+\frac{\gamma-1}{2} \mathrm{M}^{2}
\end{aligned}
$$

As the velocity (Mach number) changes under isentropic conditions, these 
relationships given by equations (12) and (13) describe the variation of the static pressure and temperature in the flow. For compressible flows, the ideal gas law is represented in the following form given by Equation (14),

$$
\rho=\frac{p_{o p}+p}{\frac{R}{M_{w}} T}
$$

where $\mathrm{p}$ is the local static pressure relative to the operating pressure while $\mathrm{p}_{\mathrm{op}}$ is the operating pressure. From energy equation, the temperature, $\mathrm{T}$ will be computed. The energy equation is represented in Equation (15) as,

$$
\frac{\partial}{\partial \mathrm{t}}(\rho \mathrm{E})+\nabla \cdot(\overrightarrow{\mathrm{v}}(\rho \mathrm{E}+\mathrm{p}))=\nabla \cdot\left(\mathrm{k}_{\mathrm{eff}} \nabla \mathrm{T}-\sum_{\mathrm{j}} \mathrm{h}_{\mathrm{j}} \overrightarrow{\mathrm{J}}_{\mathrm{j}}+\left(\bar{\tau}_{\text {eff }} \cdot \overrightarrow{\mathrm{v}}\right)\right)+\mathrm{S}_{\mathrm{h}}
$$

where the first three terms on the right side of the equation represent energy transfer owing to conduction, species diffusion, and viscous dissipation, respectively. The effective conductivity is represented by $\mathrm{k}_{\mathrm{eff}}$ (i.e. $\mathrm{k}+\mathrm{k}_{\mathrm{t}}$, where $\mathrm{k}_{\mathrm{t}}$ being the turbulent thermal conductivity, defined according to the turbulence mode), and $\overrightarrow{\mathrm{J}}_{j}$ represents the diffusion flux of species, $\mathrm{j} . \mathrm{S}_{\mathrm{h}}$ includes volumetric heat sources. $\mathrm{E}$ is described by Equation (16) as,

$$
E=h-\frac{p}{\rho}+\frac{v^{2}}{2}
$$

Enthalpy $\mathrm{h}$ is defined as,

$$
h=\sum_{j} Y_{j} h_{j}+\frac{p}{\rho}
$$

In Equation (17), $\mathrm{Y}_{\mathrm{j}}$ is the mass fraction of species $\mathrm{j}$ and,

$$
\mathrm{h}_{\mathrm{j}}=\int_{\mathrm{T}_{\mathrm{ref}}}^{\mathrm{T}} \mathrm{c}_{\mathrm{p}, \mathrm{j}} \mathrm{dT}
$$

RANS: The equations (continuity, momentum, and energy) combined as discussed in previous subsections are known as the Navier-Stokes equations (N-S). Analytical solution doesn't exist for these highly nonlinear coupled partial differential equations and therefore numerical methods are employed such as FVM as in this current study. Exact solution of $\mathrm{N}-\mathrm{S}$ equations is too much of accuracy. It captures every minute detail of turbulent flow. Averaged value is enough for engineering purposes. Instead of solving actual N-S equations and to get average values, averaged N-S equations can be solved. $\mathrm{N}-\mathrm{S}$ equations obtained after averaging is known as Reynolds Averaged Navier-Stokes equations (RANS). In Reynolds averaging, the solution variables in the instantaneous (exact) $\mathrm{N}-\mathrm{S}$ equations are resolved into the mean (time-averaged or ensemble-averaged) 
and fluctuating components. As represented in Equation (19), for the velocity components;

$$
\mathrm{u}_{\mathrm{i}}=\overline{\mathrm{u}}_{\mathrm{i}}+\mathrm{u}_{\mathrm{i}}^{\prime}
$$

where $\overline{\mathrm{u}}_{\mathrm{i}}$ and $\mathrm{u}_{\mathrm{i}}^{\prime}$ are the mean and fluctuating velocity components $(\mathrm{i}=1,2,3)$.

Likewise for pressure and other scalar quantities, Equation (20) holds as,

$$
\varphi=\bar{\varphi}+\varphi^{\prime}
$$

Where a scalar such as energy, or pressure is denoted by $\varphi$.

Substituting expressions of this form for the flow variables into the momentum and continuity equations and taking an ensemble (or time) average yields the ensembleaveraged momentum equations. In Cartesian tensor form, they can be written as in Equations (21) and (22),

$$
\begin{aligned}
& \frac{\partial \rho}{\partial t}+\frac{\partial}{\partial x_{i}}\left(\rho u_{i}\right)=0 \\
& \frac{\partial}{\partial t}\left(\rho u_{i}\right)+\frac{\partial}{\partial x_{j}}\left(\rho u_{i} u_{j}\right)=-\frac{\partial p}{\partial x_{i}}+\frac{\partial}{\partial x_{j}}\left[\mu\left(\frac{\partial u_{i}}{\partial x_{j}}+\frac{\partial u_{j}}{\partial x_{i}}-\frac{2}{3} \delta_{i j} \frac{\partial u_{1}}{\partial x_{1}}\right)\right]+\frac{\partial}{\partial x_{j}}\left(-\rho \overline{u_{i}^{\prime} u_{j}^{\prime}}\right)
\end{aligned}
$$

Equations (21) and (22) are designated as Reynolds-Averaged Navier-Stokes (RANS) equations. With the velocities and other solution variables now representing ensemble-averaged (or time-averaged) values, they have the same general form as the instantaneous N-S equations.

Menter's Shear Stress Transport (SST) k- $\omega$ Turbulence Model: Transport equations for the SST k - $\omega$ turbulence model are given in Equations (23) and (24);

$$
\frac{\partial \rho}{\partial t}(\rho \mathrm{k})+\frac{\partial}{\partial \mathrm{x}_{\mathrm{i}}}\left(\rho \mathrm{ku}_{\mathrm{i}}\right)=\frac{\partial}{\partial \mathrm{x}_{\mathrm{j}}}\left(\Gamma_{\mathrm{k}} \frac{\partial \mathrm{k}}{\partial \mathrm{x}_{\mathrm{i}}}\right)+\mathrm{G}_{\mathrm{k}}-\mathrm{Y}_{\mathrm{k}}+\mathrm{S}_{\mathrm{k}}
$$

and

$$
\frac{\partial}{\partial t}(\rho \omega)+\frac{\partial}{\partial x_{j}}\left(\rho \omega u_{j}\right)=\frac{\partial}{\partial x_{j}}\left(\Gamma_{\omega} \frac{\partial \omega}{\partial x_{j}}\right)+G_{\omega}-Y_{\omega}+D_{\omega}+S_{\omega}
$$

In Equations (23) and (24), $\omega$ is the specific dissipation rate and $\mathrm{k}$ is the turbulence kinetic energy. $G_{\omega}$ represents the generation of $\omega . G_{k}$ represents the production of turbulence kinetic energy. The effective diffusivity of $k$ and $\omega$ are represented by $\Gamma_{k}$ and $\Gamma_{\omega}$, respectively. The dissipation of $\mathrm{k}$ and $\omega$ due to turbulence are represented by $Y_{k}$ and $Y_{\omega}$, respectively. $S_{k}$ and $S_{\omega}$ are source terms equals to unity respectively, $D_{\omega}$ represents the cross diffusion term defined in Equation (25), 
$\mathrm{D}_{\omega}=2\left[1-\tanh \left[\left[\min \left\{\max \left(\frac{\sqrt{\mathrm{k}}}{0.09 \omega \mathrm{y}}, \frac{500 \mu}{\rho \mathrm{y}^{2} \omega}\right), \frac{4 \rho \mathrm{k}}{1.162 \mathrm{D}_{\omega}^{+} \mathrm{y}^{2}}\right\}\right]\right]\right] \rho \frac{1}{1.168 \omega} \frac{\partial \mathrm{k}}{\partial \mathrm{x}_{\mathrm{j}}} \frac{\partial \omega}{\partial \mathrm{x}_{\mathrm{j}}}$

where $\mathrm{D}_{\omega}^{+}$is the positive portion of the cross-diffusion term and $\mathrm{y}$ is the distance to the next surface.

\section{Thermodynamic Model}

The molecular and thermodynamic properties of the exhaust gases are evaluated using NASA CEA 400 code (Gordon and McBride 1994). Table 1 purviews the solid propellant compositional data (primary stage) such as weight fraction and energy. The composition is derived from Ammonium Perchlorate Composite Propellant (APCP) which is a modern day solid fuel rocket propellant used in rocket vehicles (Miller and Barrington 1970). Ammonium perchlorate $\left(\mathrm{NH}_{4} \mathrm{ClO}_{4}\right)$ serves as the oxidizer while Polybutadiene Acrylonitrile (PBAN) works as the elastomer binder with weight fractions of 0.69 and 0.14 , respectively. The binder and aluminum serve as the fuel. The weight fraction of aluminum is 0.16. The remaining components are HMX (Cooper 1996) (HighMolecular-weight $\mathrm{rdX}$ ) which is a powerful and relatively insensitive nitroamine high explosive and other burn rate catalysts (not accounted for). The derived cured propellant is equitably elastic, which additionally helps minimize fracturing during accumulated damage and high acceleration applications (Douglass et al. 1971).

Table 1. Solid fuel composition.

\begin{tabular}{lcc}
\hline Reactant & $\begin{array}{c}\text { Weight } \\
\text { Fraction }\end{array}$ & $\begin{array}{c}\text { Energy } \\
(\mathrm{kJ} / \mathrm{kg}-\mathrm{mol})\end{array}$ \\
\hline PBAN & 0.14 & -63220.00 \\
$\mathrm{HMX}$ & 0.01 & -86.00 \\
$\mathrm{NH}_{4} \mathrm{CLO}_{4}$ & 0.69 & -295767.00 \\
$\mathrm{Al}$ & 0.16 & 0.00
\end{tabular}

The solid propellant combination is considered at ambient temperature, for a nominal chamber pressure of 100 bar. In the CEA 400 code, subroutine ROCKET is the control program for rocket performance calculations. It is called from the main program if the problem type $r k t$ or $r o$ is included in the prob dataset. Subroutine ROCKET selects the appropriate iteration scheme for the assigned combustion chamber model fac or iac. By calling subroutine EQLBRM, it obtains the required thermodynamic properties for equilibrium performance. It calls subroutine TRANP to obtain thermal transport properties if trn or tran has been included in the outp dataset. The assignment of parameters for various points in the rocket problem is handled by various loops. An outer loop calls NEWOF for each new value of oxidant-to-fuel ratio. Another loop assigns 
chamber pressures. There are other loops inside for assigned exit conditions. For the exit conditions, assigned pressure ratios, if any, are processed first; then, assigned subsonic area ratios, if any; and finally, assigned supersonic area ratios, if any. Subroutine RKTOUT is called for preparing output tables when either a page is filled ( $\mathrm{Npt}=\mathrm{NCOL}$ ) or all exit points have been calculated for equilibrium compositions. The input code is as follows:

- prob case $=12354543$ ro equilibrium

- $\quad$ iac problem

- p,bar 100

- $\quad$ supar 2.928571429

- $\quad$ pip 10000000

- reac

- oxid PBAN wt $\%=14.00 \mathrm{t}, \mathrm{k}=298.15$

- oxid HMX wt $\%=1.00 \mathrm{t}, \mathrm{k}=298.15$

- $\quad$ oxid NH4ClO4(I) wt $\%=69.00 \mathrm{t}, \mathrm{k}=298.15$

- $\quad$ oxid $\mathrm{Al}(\mathrm{cr}) \mathrm{wt} \%=16.00 \mathrm{t}, \mathrm{k}=298.15$

- insert $\mathrm{C}(\mathrm{gr})$

- insert $\mathrm{Al} 2 \mathrm{O} 3(\mathrm{~L}) \mathrm{Al}_{2} \mathrm{O}_{3}(\mathrm{a})$

- output short

- $\quad$ output trace $=1 \mathrm{e}-5$

- end

The thermochemical parameters of the exhaust gases with their corresponding steady state values at three different axial positions, i.e.; chamber, throat, and exit of the rocker nozzle are obtained from CEA 400 code.

Table 2. Exhaust properties.

\begin{tabular}{llll}
\hline Parameters & Chamber & Throat & Exit \\
\hline Pressure $(\mathrm{bar})$ & 100 & 57.97 & 0.51 \\
Temperature $(\mathrm{K})$ & 3422.79 & 3215.68 & 494.07 \\
Density $\left(\mathrm{kg} / \mathrm{m}^{3}\right)$ & 9.80 & 6.04 & $7.86 \mathrm{e}-5$ \\
Specific heat $(\mathrm{kJ} / \mathrm{kg} . \mathrm{K})$ & 3.30 & 2.99 & 4.84 \\
Enthalpy $(\mathrm{kJ} / \mathrm{kg})$ & -1825.54 & -2365.02 & -8391.88 \\
Internal Energy $(\mathrm{kJ} / \mathrm{kg})$ & -2835.22 & -3307.53 & -8517.75 \\
Gibbs Energy $(\mathrm{kJ} / \mathrm{kg})$ & -33951.10 & -32546.70 & -13029.10 \\
Specific impulse, $\mathrm{I}_{\mathrm{sp}}(\mathrm{m} / \mathrm{sec})$ & $\mathrm{NA}$ & 1038.70 & 3623.90 \\
\hline
\end{tabular}


The physical quantities of pressure, temperature, density, specific heat, enthalpy, internal energy, Gibbs energy are taken only space dependent not time dependent and tabulated in Table 2. The pressure drops from a chamber pressure of 100 bar to 0.51 bar. Temperature and density drops are also observed. Internal energy as well as enthalpy gets more negative while there is an increase in free energy.

\section{Discretization}

The CFD tool utilizes finite volume approach. The differential conservation equations are integrated over a control volume described around a node to obtain an integral equation. The spatial derivative terms in the integral equations and the pressure integral terms in the momentum integral equation are also evaluated using finite element approach. The set of discretized equations form a set of algebraic equations and the solution vector is approximated by Gauss-Seidel algorithm in which the solver employs an iterative method to update the solution vector in each iteration.

\section{Boundary and Initial Conditions}

In Fig. 2, the computational domain through which the exhaust gases flow, is shown with the location of applied boundary conditions for the simulation marked on it. At the domain inlet, subsonic boundary condition has been used with pressure and temperature obtained from the thermodynamic model section. On the wall a no slip adiabatic boundary condition is employed and outlet is modeled with supersonic boundary condition also obtained from the thermodynamic model section. Detailed flow simulation is not opted to be reported adequately here. For time stepping, automatic fluid time step option has been chosen. The thermochemical parameters are listed in Table 1 and 2. It takes around 500 steps for the convergence.

\section{RESULTS AND DISCUSSION}

Static pressure variation with the normalized axial location across the wall is shown in Fig. 3. It can be noticed that there is higher static pressure in the tube compared to the throat region. Pressure drop within the blast tube is $10.06 \%$. This indicates negligible loss in pressure in tube whereas in the nozzle pressure loss is significant. Figure 4 depicts the static pressure distribution in color-filled contour or profile (often referred to as a "carpet plot") superimposed on the physical domain. Along a reference vector, the profile plot draws the contours projected off the surface by an amount equivalent to the value of the variable plotted at each point on the surface. Red color regions represent higher values in the magnitude of the depicted variable where blue color regions represent lower values in the magnitude of the depicted variable. 
Table 3. Mesh quality optimization.

\begin{tabular}{|c|c|c|c|}
\hline \multirow{2}{*}{$\begin{array}{l}\text { Nodes/ } \\
\text { Elements }\end{array}$} & \multicolumn{2}{|c|}{ Aspect Ratio } & \multirow{2}{*}{$\begin{array}{l}\text { \% Variation in Static } \\
\text { Pressure at Throat }\end{array}$} \\
\hline & Average & Std. Deviation & \\
\hline $15190 / 13908$ & 3.58 & 1.26 & 1.50 \\
\hline $17514 / 16306$ & 3.93 & 1.65 & 0.68 \\
\hline $18655 / 17280$ & 3.75 & 1.29 & 0.01 \\
\hline $19800 / 18330$ & 3.81 & 1.45 & 0.00 \\
\hline $21306 / 19800$ & 4.02 & 1.95 & 0.00 \\
\hline
\end{tabular}

Grid independence studies have been carried out with different nodes and elements. This optimization was done by refining the mesh until static pressure at throat region converges to a steady value with minimal variation. The percentage variation in consecutive iteration for different sets of nodes and elements is tabulated in Table 3 . Best results are found by considering 18,655 nodes and 17,280 elements.

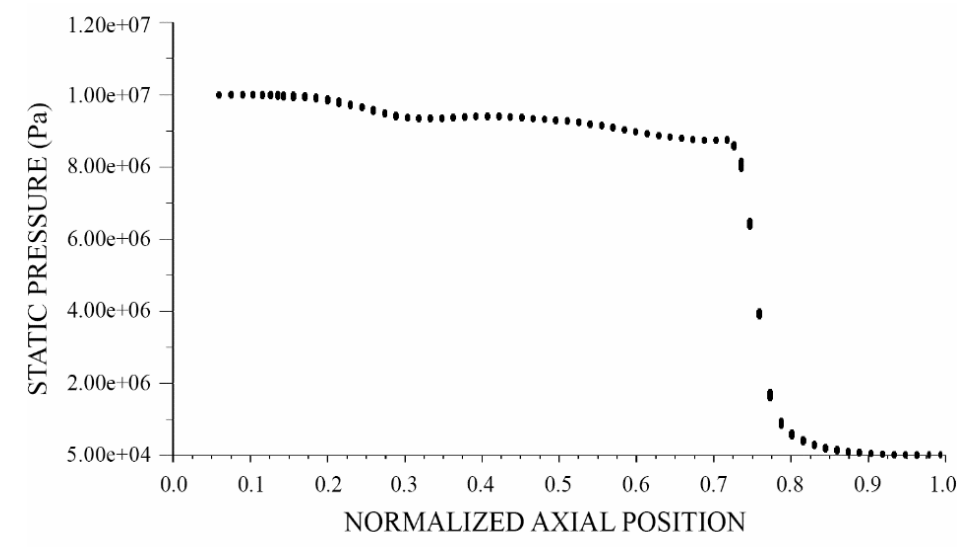

Fig. 3. Static pressure variation with axial position.

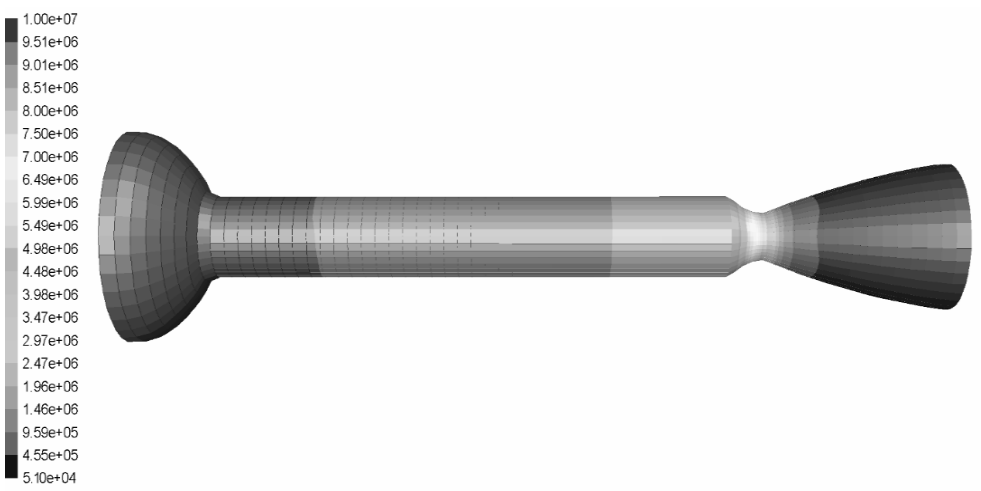

Fig. 4. Static pressure distribution across the wall. 
Velocity variation in terms of Mach number with the normalized axial location is shown in Fig. 5. Up to the throat region, the exhaust gas has a subsonic velocity profile and beyond that it is driven to a supersonic profile. Mach distribution is depicted in colorfilled contour superimposed on the physical domain in Fig. 6. Blue color regions represent lower values in the magnitude of the depicted variable which is Mach number while the color shifts to red as values rise in magnitude.

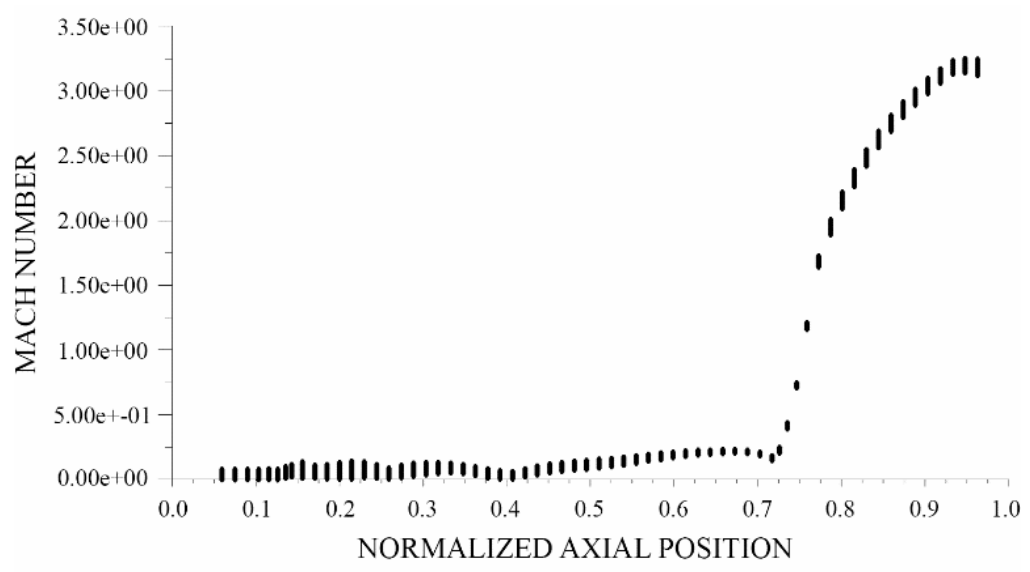

Fig. 5: Mach number variation with normalized axial position.

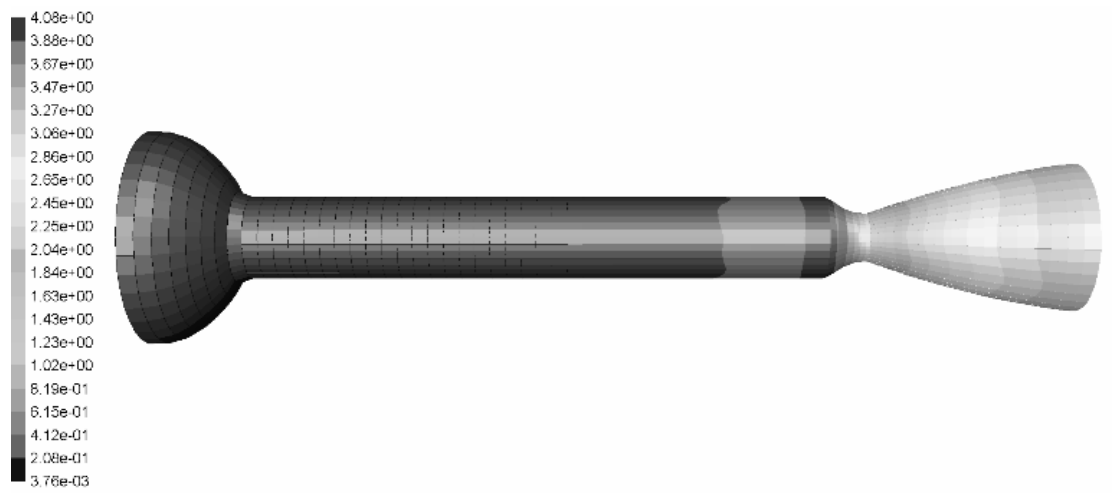

Fig. 6: Mach number distribution across the wall.

As in the simulation, the nozzle chokes at the throat as the mass flow through the nozzle and the pressure is adequate to reach sonic speeds, otherwise supersonic flows would not be achieved. This requires the entry pressure to the nozzle (100 bar in this study) to be significantly above ambient all the time. In addition, the pressure of the exhaust gases at the exit of the exit cone, which is the expansion region of the nozzle, 
must not be very low. This is because pressure cannot travel upstream through the supersonic flow. The exit pressure of the gases can be significantly below the ambient pressure into which they exhaust, but it cannot be too far below ambient. If this happens, the flow will no longer be supersonic, or the flow will separate within the expansion region of the nozzle forming an unstable jet that may flop around producing a lateral thrust and possibly damaging the nozzle. It is found out that ambient pressure is roughly as high as 2 times the pressure of the supersonic gas at the exit of the nozzle. This signifies an expected outcome in design perspective.

\section{CONCLUSION}

The flow field through the control volume is computed by solving ReynoldsAveraged Navier-Stokes (RANS) equations with Menter's Shear Stress Transport (SST) $\mathrm{k}-\omega$ turbulence model using a CFD tool like FLUENT. The thermochemical and hydrodynamic aspects are evaluated and the tradeoffs are studied for a certain configuration of the rocket motor (from dome-closeout onward). It is found out that the implementation of thrust vectoring mechanism amounts to an additional pressure loss of $10.06 \%$ in the rocket motor. It is also found out that the hydrodynamic characteristics of the optimized rocket motor (from dome-closeout onward) is congruent with the overall mission and payload criteria of the flight vehicle as it applies to SRBMs.

\section{REFERENCES}

Batchelor, G. K. 1967. An Introduction to Fluid Dynamics. Cambridge University Press, Cambridge, England.

Carlson, D. J. and R. F. Hoglund. 1964. Particle drag and heat transfer in rocket nozzles. AIAA Jour. 2(11): 1980-1984.

Chow, A. and K. R. Jin. 1991. Modeling flow at the nozzle of a solid rocket motor. AIAA Joint prop. Conf. 27: 10.2514/6.1991-2432CP

Cooper, P. W. 1996. Explosives Engineering. Wiley-VCH, New York.

Douglass, H.W., J. H. Collins and W. H. Miller. 1971. NASA Solid rocket motor performance analysis and prediction (Space Vehicle Design Criteria (Chemical Propulsion)). NASA Lewis research center, Rocket science institute.

Fleeman, E. L. 2001. Tactical Missile Design. AIAA Inc., Reston, Virginia.

Gordon, S. and B. J. McBride. 1994. Computer program for calculation of complex chemical equilibrium compositions and applications-I. Analysis, NASA RP-1311. Office of Management, Scientific and Technical Information Program.

Gordon, S. and B. J. McBride. 1994. Computer program for calculation of complex chemical equilibrium compositions and applications-II. User's manual and program description, NASA $R P$-1311. Office of Management, Scientific and Technical Information Program.

Hoeijmakers, H. W. M. 1988. The role of computational fluid dynamics in missile aerodynamics. NEAR conf. on missile aerodynamics 7: 1580-607. 
Menter, F. R. 1994. Two-equation eddy-viscosity turbulence models for engineering applications. AIAA Jour. 32(8): 1598-1605.

Miller, W. H. and D. K. Barrington. 1970. A review of contemporary solid rocket motor performance prediction techniques. J. Spacecraft and Rockets 7(3): 225-37.

Sutton, G.P. and O. Biblarz. 2001. Rocket Propulsion Elements. John Wiley \& Sons Inc.

Tahsini, A. M. and M. Ebrahimi. 2006. Blast tube effects on internal ballistics of SRM. AIAA/ASME/SAE/ASEE Joint Prop. Conf. \& Ex. 42: 10.2514/6.2006-4958.

Taylor, T. S. 2009. Rocket Science and Engineering. CRC Press, Taylor \& Francis Group, LLC.

(Received revised manuscript on 7 June, 2017) 